\title{
Editorial: The Culture of Sovereignty - and War
}

Why devote an issue of Culture and Dialogue to "war and sovereignty"? The dialogue is at the heart of the question of sovereignty, its possibility, its need and justification. Aspirations for sovereignty do not only concern territories and proprieties in the concrete sense of the terms. We find issues of sovereignty in all layers of life; academia, science, business, the judiciary, or religion, amongst others. Questions of sovereignty have affected individuals as much as groups of people of all sizes in all parts of the globe. Drives to establish sovereignty have mapped the history of humanity and continue to do so. In other words the question concerning sovereignty is universal, both in space and time.

Any conception of sovereignty thought to be inalienable and indivisible, as for Jean-Jacques Rousseau amongst others, is fundamentally misled. Worse, such conception can be the trigger of one of the ugliest demeanours of human experience: war - whether or not it is justified when it serves a commendable purpose outside of itself, as Carl von Clausewitz believed. Just as there is no immutable identity in-itself, there is no such a thing as the inalienability or indivisibility of sovereignty. This is not to say that sovereignty (or identity, for that matter) is a flawed conception that should be thrown into the dustbin of alleged progressive civilisations. Rather, sovereignty should be understood in relational terms, practised ethically, and determined according to circumstances. By nature and by definition, sovereignty understood as the practise of authority in order to create, preserve, or impose a closure, is profoundly relational; sovereignty is established according to criteria that determine the inside and outside of its own closure. It is at this point that metaphysical conceptions of sovereignty can pave the way for conflicts and other atrocities. Depending on the chosen criteria, insiders may feel the need to define themselves as outsiders; conversely, outsiders may resist a sovereign's will or strategy to convert themselves to being insiders. There can be neither any abstract Leviathan nor a supreme individual, as in Jean Bodin, who operates at will regardless of the relation and circumstances. In other words, sovereignty must remain ethical before being metaphysical.

Sovereignty is fundamentally human, and as such it must be chosen and decided by the very humans who enact such a sovereignty, that is, not by other individuals, ideologies, or even the divine. But even in the form of contract as 
Thomas Hobbes suggested, ignoring the voice of others in the name of sovereignty runs against nature; the possibility of and justification for sovereignty can only be established on ethical and concretely human grounds. There is no such a thing as inalienable and indivisible sovereignty because of its naturally concrete relational complexion. Sovereignty abstracted from its human, dialogical concreteness betrays drives for the kind of instrumentality that seeks power and control over the others, including the ones who happen to be outsiders within the boundaries of the closure at stake. Sadly, histories and cultures do not fall short of selective criteria that justify claims for such conceptions of sovereignty, not only in the name of civilisation, political ideals, or of a better god, but also for reasons of ethnic origins, traditions, language, geography and mercantile profit. Nations and communities will claim sovereignty according to notions of historical origins, common language, natural topology or freedom of trade that suit their aspirations or situations. But, as such, not all aspirations for and exercise of sovereignty should be seen as condemnable for their coercive power-seeking and control over persons, groups, or other human entities. Just as there is, for Paul Ricoeur, "good and bad subjectivity" in historiography, there is good and bad sovereignty in the ways humans have striven to establish themselves and sought recognition. The quest for sovereignty has been used as a tool for either liberation or coercion. In the former case, the outsider within the same does not recognise itself; in the latter the insider ignores the other in the name of inalienability and indivisibility legitimised by subjectively chosen criteria that feed and meet desires for power and control. Still, the good sovereignty thus defined is always in danger of betraying itself should it yield to the temptation of believing in the illusion of its own immutable substance and thereby renounce to relate to the other in mutually considerate and renewing fashion; namely in a civilised way.

The exercise of sovereignty being fundamentally relational, it seems sadly unavoidable that pretenders who do not understand the nature of the relation will seek to reach their goal by less than commendable means such as repression, war and destruction. The questions of the justification, establishment and recognition of sovereignty are at the core of the possibility of a liveable world.

Biraj Mehta Rathi discusses these very issues within the contemporary context of India by suggesting that Rabindranath Tagore's conception of cosmopolitanism may offer a more concretely ethical alternative to John Rawls' relational views on nations and people(s). Tagore's version of cosmopolitanism developed within a specific historical, cultural and national context, which is different from that of most Western theorists such as Rawls or Martha 
Nussbaum. Metha subsequently suggests considering Jacques Derrida's "paradoxical understanding of hospitality, friendship and otherness" that would include "subaltern" cultures and identities for a more just and therefore liveable world.

Eric Nsuh Zuhmboshi equally questions a particular conception of sovereignty and how it has been exercised in a specific cultural context, that of predominantly French-speaking Cameroon. What is at stake here is the practicality of Jean-Jacques Rousseau's idealistic conception of the "social contract" that becomes irrelevant and even, in the worse cases, traumatic in particular post-colonial societies whereby the state becomes an "aggressive apparatus" that does not "protect the citizens and guide them in their aspirations." To illustrate his point about such ill-guided conception of state-sovereignty that privileges dominant cultural forces, Zuhmboshi invites us to consider two particularly topical literary works, but in a style that both theorizes and brings us into the narratives themselves: Helon Habila's Waiting for an Angel and John Nkemngong Nkengasong's Across the Mongolo.

Wisam Kh. Abdul-Jabbar and Sabah Wajid Ali discuss the possibility of addressing unwelcomed sovereignties by non-conflictual means. The context of post-Saddam Iraq far from having resolved the question of liveable sovereignty, has actually given way to a new form of sovereign illegitimacy; that of the predominantly-Western coalition whose endeavour to liberate Iraq has translated into a form of colonisation. This absurd situation does not, however, need to lead to all too familiar acts of terrorism that justify themselves as means for the right end. Instead, some English-speaking Iraqi bloggers use a much more humanly powerful weapon of resistance that shows how Iraq as a "theatre of war" has mutated into a "theatre of the absurd." This weapon is sarcasm.

There is, in fact, no better way to understand the nature of conflicting sovereignties than to look into the working processes of relations themselves. This is also what allows for a better appraisal of what has been and can be done to build peace in areas of conflicts. Julia Amos examines the sources of interethnic violence in the context of Ghana and discusses the extent to which more neutral entities such as NGOs can provide relational platforms that accommodate various needs and drives for sovereignty in order to "transcend the violence." In this case, far from being an abstract relational contract with universal pretentions, the entities at work consider the particular forms of aspirations and conditions whether in terms of state or ethnic groups.

The experience of sovereignty can also take a very idiosyncratic and unexpected shape, albeit equally problematic in terms of potential trauma, violence and harm. Instead of seeking to establish one's own boundaries, whether for 
the sake of domination or survival, utmost sovereignty may lie in one's ability to experience precisely the dissolution of such boundaries. This quasi-mystical conception of sovereignty is allegedly what the self goes through in ec-static experiences of ecstasy. Meng-Shi Chen discusses the reasons why Georges Bataille famously offered such an unusual account of sovereignty from his own perceptual experiences of the unbearable images of the Chinese lingchi tortures and executions. Bataille's "obsession," then, is no more than the same drive for sovereignty that has always characterised human nature and that has been channelled in most despicable or enriching ways depending on time, space and circumstances.

Finally, in our Outlook section, Sachin Siwakoti discusses the possibility of an inclusive form of cosmopolitanism from an Asian perspective, implying thus that any allegedly universal standard of ethical values is by nature perspectival. Tracing the roots of cosmopolitanism in the history of Asian civilisations whether in spiritual practices (Buddhism and Jainism), language (Sanskrit) or Chinese culture (Tian Xia), allows for different cultural standpoints to emerge. The "way forward", therefore, is to nurture an inter-civilisational dialogue when it comes to envisaging a shared sense of liveable sovereignty for all.

As always, I thank my editorial colleagues for all their support and good will: Martin Ovens, Loni Reynolds and Erika Mandarino; all the Editorial Board members of the Journal; the anonymous reviewers; and all the contributors to this issue on "Culture, War and Sovereignty." A special thank also to Robert Clarke for his review of Dylan Craig's Sovereignty, War and the Global State. The next issue of the Journal will be Guest-Edited by Felix O. Olatunji, of Ladoke Akintola University of Technology (Nigeria), on the topic of "African Thought and Dialogue" (Volume 8, Number 1, 2020).

\section{Gerald Cipriani}

